\title{
A LIFE-HISTORY CASE STUDY ON SELF-RELIANCE EXPERIENCE OF DIVORCED MIGRANT WOMEN
}

\author{
SooAn Choi ${ }^{1}$, \& YoungSoon Kim ${ }^{2}$ \\ ${ }^{I}$ Doctoral student, Dept. of Multicultural Education, Inha University (South Korea) \\ ${ }^{2}$ Professor, Dept. of Multicultural Education, Inha University (South Korea)
}

\begin{abstract}
This study aims to examine the life history of migrant women who have experienced divorce in a socio-cultural context. Five people participated in the study, and they have been living in self-reliance support facilities since their divorce. They were selected from interviews on the life history of 80 married migrant women, which were funded by the Korea Research Foundation from 2017 to 2019. The method of research is a life-historical case study. The results of the study are as follow; first, their marriage was to escape gender hierarchy and poverty in their home country. Therefore, it was confirmed that marriage migration took place within the transnational trend of feminization of migration. Second, self-reliance support facilities provide strong social support for divorced migrant women. As a result, it works as an important space that allows them to escape from voluntary self-exclusion and explore new subjectivity. Suggestions of the implications are as follow; the social support from self-reliance support facilities after divorce is a driving factor that is the subjective and active effort of single-parent migrant women. Discussions should continue that those who are free from the spouses of the people can live as practical and public citizens of Korean society.
\end{abstract}

Keywords: Divorced migrant women, self-reliance experience, self-reliance support facility, life-history case study.

\section{Introduction}

In Korea, marriage migrant women emerged as part of a project to solve the marriage problem of rural bachelors in the 1980s. Since the 1990s, the number of married migrant women has increased gradually. In 2009, there were about 33,000 international marriages, accounting for $10 \%$ of the total for the first time (Statistics Korea, 2020). The spread of capitalism at the global level has amplified the feminization of women from underdeveloped countries in Southeast Asia. In this new order, Korea aims to maintain patriarchal gender division through a new marriage system called international marriage. It also aims to solve social reproduction and care labor problems (Kim, 2016). In other words, the migration of migrant marriage women to Korea goes beyond personal life and choice. Their migration can be seen as having a great impact on the socio-cultural context.

Meanwhile, more migrant women are experiencing divorce as much as the increase in marriage. It accounted for 12.6 percent of all divorces in 2011, with an average annual rate of 9 percent (Statistics Korea, 2020). After divorce, most migrant women experience a sense of loss and the burden of self-reliance on a new life. Furthermore, they face limitations on social relations within Korean society. (Lee, 2013). The Seoul Metropolitan Government opened a self-reliance support facility for migrant women in 2010 to help them stand on their own feet. However, it is difficult to find research on women using that area. Therefore, this study aims to examine the experience and meaning of self-reliance support facilities in the context of their life history.

\section{Research method}

\subsection{A life-history case study}

To study life history is to place personal experiences in historical and social contexts. This is a useful way to interpret the meaning of a particular experience and event (Kim, 2012), i.e., personal perspectives that emerge throughout life history reveal a person's special situation. At the same time, it reveals the universal culture to which the individual belongs (Choi, 1999). The migrant women chose to 
go to Korea for patriarchal hierarchies and economic difficulties in their home countries. Behind it is the great trend of womenization of migration. However, marriage immigration also has its own self-determination. Kim (2014) says this uncertainty in married migrant women types them as "internal strangers," not outsiders or insiders. Kim (2014) also points out that Korean society portrays women as immoral subjects who easily choose divorce. Sociocultural influence resides in the lives of migrant women who have experienced marriage and divorce. This cannot be overcome entirely by individual power.

This study aims to capture the voices of migrant women who live in self-reliance support facilities after divorce and prepare for independence. Self-reliance support facilities are the only places in Korea that provide a solid sense of intimacy. Therefore, we would like to examine how the experience here relates to the self-reliance process. Through life-history case study, we will be able to bring their experiences to life more vividly.

\subsection{Research participants}

Five people were selected as research participants in interviews with 80 married migrant women from 2017 to 2019. The criteria for selection were for those who lived in self-reliance support facilities for migrant women after divorce or separation. Only one facility in Seoul is operated to support the independence of migrant women. This place allows single-parent migrant women who have experienced domestic violence and their accompanying children to enter the facility and receive support necessary for self-reliance and self-support. The maximum residence period of the facility is two years. It operates Korean language education, employment education, parent education, and programs for children. The basic information of the participants is shown in Table 1.

Table 1. Participant Information

\begin{tabular}{|c|c|c|c|c|c|c|c|}
\hline No. & Age & $\begin{array}{c}\text { Period of } \\
\text { Residence }\end{array}$ & Status & Origin Country & $\begin{array}{c}\text { Type of } \\
\text { marriage }\end{array}$ & $\begin{array}{c}\text { Form of } \\
\text { marriage }\end{array}$ & $\begin{array}{c}\text { Child } \\
\text { (age) }\end{array}$ \\
\hline 1 & $25 \mathrm{y}$ & $6 y s$ & F-6 & Vietnam & Agency & First/First & $2(3,6 y)$ \\
\hline 2 & $27 y$ & $5 y s$ & F-6 & Vietnam & Introduction & First/Re & $1(4 y)$ \\
\hline 3 & $28 y$ & $7 y s$ & F-6 & Cambodia & Introduction & First/Re & $1(7 y)$ \\
\hline 4 & $37 y$ & $7 y s$ & F-6 & Vietnam & Agency & Re/Re & $1(4 y)$ \\
\hline 5 & $28 y$ & $4 y s$ & F-6 & Vietnam & Agency & First $/ \operatorname{Re}$ & $2(5,3 y)$ \\
\hline
\end{tabular}

The basic information of participants is as follow; their ages range is from 20 s to 30 s and average residence period is 5.8 years. All of them are eligible to stay in F-6 (marriage visas) and have not obtained permanent residency or nationality. The reason for being a marriage visa is that it can be maintained if a Korean spouse divorced due to an attributable reason. Their marriage type is all introductory marriage. Also, if you look at the marriage type, all husbands are remarried except for participant 1. All participants are staying at the facility with their children, and in the case of Participant 1, the first child lives with her ex-husband. Participant 4's ex-marriage children live in Vietnam and want to bring their children with them when she achieves independence.

\section{Research Results}

\subsection{Before divorce}

There are a number of factors affecting gender composition in international migration flows. It is immigration legislation in the country of acceptance, selective foreign labor demand according to gender, and changes in gender relations in the country of origin (Carling, 2005). The conditions of labor migration are tricky in Korea. Therefore, women from Southeast Asia chose to move to marry to make a living for their families. They want to escape gender inequality that exists in their country of origin and dream of a better life through international marriage with hope for Korean life. However, their purpose is not achieved. Because it is a little different from the reason why Korean husband chose international marriage. What Korean husbands wanted was a person who took good care of their ex-married children and worked in accordance with patriarchal culture.

"Work only at home. Do you know why I brought you here? You have to take good care of my parents!" That's what my ex-husband says. Disappointed." -Participant 3

Other participants, except for Participant 4, were divorced due to tangible and intangible violence by their husbands and families. They endured violence and hesitated to divorce their children in order to give them a full home. But eventually, it leads to divorce. Participant 4 still does not know the 
reason for the divorce. However, she seems to think her ex-husband thought that if Participant 4 made her money, she might go back to Vietnam. She only speculates that this was the cause of her divorce.

"I think the Chinese people who lived in the same neighborhood said, "If she makes money, she will go to Vietnam or not live in Korea." That's why my husband believes that, and I think he got divorced right away." -Participant 4

From the perspective of Sassen (2002)'s "feminization of survival," participant 4 has more inevitable economic support relations to Vietnamese family than other participants. Therefore, her can be seen as one of the survival strategies. Korean families want to incorporate her into Korea's paternalistic family relationship. However, due to the hybrid nature of participant 4 , the ex-husband decided that he would not be able to achieve this goal.

\subsection{Transition}

In Korea, there is a tendency to find the basis of migrant women's policy support in terms of Korean wife and Korean mother (Hwang, 2012). From the pre-divorce period, they realize that their rights can be decided by their husbands. In other words, they face the reality that they are not recognized as whole subjects and are treated as others.

"If you get divorced, say, "Go to Vietnam." Said her husband all the time. It wasn't good, but I couldn't do anything. She was afraid to leave the baby. Everyone in my Vietnamese families thought so." - Participant 5

Participant 1 has not shown any experience in this transition period. Unlike other participants, she divorced her husband on her own will, and this seems to have had an impact. Li (2021) categorized migrant women's divorce types into dominant, institution-driven, and non-dominant. The dominant type refers to the case of choosing a divorce by one's will. People of this type have already experienced psychological confusion before the divorce, and that is why after the divorce, a willingness to quickly adapt to the changed life appears. In addition, Participant 1 expressed her own negative emotions in conflict situations during her marriage, and took these expressions for granted. In other words, it can be said that she has a strong self-esteem. This personal disposition also seems to have an effect on the transitional experience.

"I was angry and threw it away. I mean, when I'm angry, I hate him so much. I don't want to see it, and I think it's a natural feeling." - Participant 1

\subsection{Self-reliance period}

Divorce causes migrant women to lose their spouse status of the people. But this is not necessarily hopeless. Rather, it is a driving force for self-reliance as a subject with a new purpose in a new environment. Li (2021) mentioned three things that affect the changes and growth since becoming a single parent. They are 'religious beliefs,' 'social support,' and 'personal efforts.' This study identified the interaction between 'social support' and 'personal effort'. Social support is more important than anything else to move toward self-reliance. 'Support facilities' become a place to provide strong social support to them (Im, 2016). Social support can be formed by all forms of interaction with others (Cobb, 1976), and this interaction is the driving force behind 'personal effort'.

"The child and I tried not to understand each other. Whenever I had a hard time, I yelled at my child. My relationship with my child continued to deteriorate, and my child was stressed out. So he stood up and peed. He peed and looked at me, and it made me so angry. I didn't know what to do, and I didn't know how to raise my child. I was educated here, and now I can understand each other with my child." Participant 2

Through programs provided at support facilities, it helps to restore relationships with children and to build psychological stability to raise children on their own. In addition, the private relationship network formed here plays a role in taking care of and healing each other's pain.

"I was also stressed at first. But because I studied hard, I passed. Now I can talk to other people too. "If you work a little hard, you can do everything." It's all stressed out at first. tiring." -Participant 5

Behind the marriage process of immigrant women, there is a provisional agreement that they must comply with the new hierarchical order of patriarchy in Korea from patriarchy in their home country 
and take responsibility for the livelihood of their home country. This is called Modus Vivendi (Kim, 2016). However, the divorce made Modus Vivendi no longer effective. The provisional agreement is abolished, and several aspects emerge in the process of entering into a new agreement. Participant 1's divorce provides an opportunity to better understand the position of the husband and each other, and Participant 2 hides the fact of the divorce from his parents. Participant 3, 4, and 5 are also supported by their origin family about divorce. In addition, they get away from the difficult situation they had to come to Korea, receive vocational education in an independent facility, and recall their forgotten dreams.

"My mom says she's sorry now. At that time, she was so upset that she could not support her daughter's heart. She now says 'my daughter is doing well' and she comforts me a lot." -Participant 3

"(Beauty) I've liked it since I was young. My parents didn't let me because we didn't have enough money. (omitted). I didn't know I was this good." - Participant 1

Korean society is a patriarchal society that values paternal lineage. In this atmosphere, marriage immigrant women are forced to act as mothers, daughters-in-law, and wives (Kim, 2016). The Multicultural Family Support Act in Korea only recognizes families composed of Korean spouses and marriage immigrants as multicultural families. In addition, multicultural policies are dealt with only in terms of family maintenance and child rearing of marriage immigrants. Therefore, after divorce, women feel fear that they cannot be reborn as subjects with "my name". This is because the legal authority of the husband has been recognized by the country. Nevertheless, they fully recover their name through support facilities and prepares to move forward as a subject in a new position.

"I like calling my name the most. I'm getting bigger and more thoughtful here. If I live with my husband, I can't learn Korean and I have to stay at home. But I can go to the government office and make documents. I'm proud to be able to do anything on my own." - Participant 2

\section{Conclusions and discussions}

This study intended to address the self-reliance experience of divorced migrant women in a socio-cultural context. Migrant women regarded migration to Korea as an escape from poverty and patriarchal hierarchy in their home countries. However, they face divorce due to unexpected Korean life and tangible and intangible violence by their husbands and families. Divorce places them in a different socio-cultural position than marriage. In the process, self-reliance support facilities supported to stand on their own feet within the changed social position. It takes care of psychological difficulties and helps raise children. It comforts each other through self-help gatherings and helps find myself that I haven't found in my home country.

Participants' marriage migration process did not deviate from the ideology of "feminization of migration." However, after the divorce, they want to gain strong social support through self-reliance support facilities and become independent members. In the post-divorce process of poverty, 'heteronomous exclusion' and 'voluntary self-exclusion' appear in social relationships (Kim, 2012). It was confirmed that self-reliance support facilities are the driving force for migrant women to escape from voluntary self-exclusion. Practical discussions should be carried out so that migrant women, not the spouses of the people, can overcome the heteronomous exclusion in Korean society. In addition, it suggests in-depth follow-up research on the self-reliance experience of migrant women by examining the post-retirement process of self-reliance support facilities.

\section{References}

Carling, J. (2005). Gender dimension of International Migration. Global Commission on International Migration (GCIM). Global Migration Perspectives. 35.

Choi, Y. S. (1999). Collecting Qualitative Data. Anthropology of education, 2(2), 1-22.

Cobb, S. (1976). Social support as a moderator of life stress, Psychosomatic medicine, 38(5), 61-82.

Hwang, J.-M. (2012). Positioning Migrant Mothers in a Multicultural Society: Realities, Discourse, and New Perspectives in Korea. The Journal of Asian Women, 51(2),03-142.

Im, G. B. (2016). The Effect of Social Support of Battered Immigrant Women on Willingness to Become Self-Reliant: Focusing on Mediating Effect of Social Adjustment and Moderating Effect of Social Exclusion (Doctoral dissertation, Kyonggi University, South Korea). Retrieved from http://www.riss.kr/link?id=T14201828 
Kim, E. J. (2016). Married Immigrant Women's Life and Global Care Work Context (Doctoral dissertation, Chung-Ang University, South Korea). Retrieved from http://www.riss.kr/link?id=T14170685

Kim, J. H. (2012). Impoverishment of Unprivileged Divorcees: Their Social Exclusion Experience in family and Labor market. Korean Journal of Family Social Work, 38, 69-102.

Kim, S. E. (2012). Life History of the Dismissed Journalists: Focused on Dong-A Committee for Free Press. Korean Journal of Journalism \& Communication Studies, 56(3), 292-319.

Kim, S. N. (2014). Precarious Life and Life Mapping Strategies in Migrant Women's Experiences of Marriage and Divorce in Korea. Journal of Korean Women's Studies, 30(4), 189-231.

Lee, H. J. (2013). A Study on Child Care Work and Lives of Immigrant Single Moms. Journals of Women's Studies. 23(1). 171-214.

Li, C. (2021). A Life-historical Narrative Study on the Growth Experiences of Single-parent Migrant Women (Doctoral dissertation, Inha University, South Korea). Retrieved from http://www.riss.kr/link?id=T15773818

Sassen, S. (2002). Global Cities and Survival Circuits. In B. Erenreich and A.R. Hochschild (eds.). Global Woman: Nannies, Maid, and Sex Workers in the New Economy. New York: Metropolitan Books.

Statistics Korea (2020). Multicultural demographics. Retrieved January 10, 2021, from http://kostat.go.kr/assist/synap/preview/skin/doc.html?fn=synapview385962_1\&rs=/assist/synap/pr eview 